\title{
CrystEngComm
}

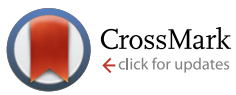

Cite this: CrystEngComm, 2014, 16 10235

\section{A structural investigation of novel thiophene- functionalized BEDT-TTF donors for application as organic field-effect transistors $\dagger$}

\author{
Qiang Wang, $t^{\mathrm{a}}$ John D. Wallis, ${ }^{\mathrm{b}}$ Yiliang $\mathrm{Wu}^{\mathrm{c}}$ and Melanie Pilkington*a
}

\begin{abstract}
Three new unsymmetrical thiophene-functionalized bis(ethylenedithio)tetrathiafulvalene (BEDT-TTF) donors (1-3) have been synthesized, characterised and examined as semiconducting materials for organic field-effect transistor (OFET) devices. The X-ray crystal structures of (1) and (2) reveal both neutral donors pack as dimers with lateral S...S contacts. For (1) the molecules are co-facially stacked in a head-to-tail manner with some degree of latitudinal slippage. A device prepared from a crystalline thin film of (1) deposited on unmodified silicon wafer substrate displays a mobility of $5.9 \times 10^{-3} \mathrm{~cm}^{2} \mathrm{~V}^{-1} \mathrm{~s}^{-1}$ with an on/off ratio of 11. The shorter $\mathrm{CH}_{2}$ linker in (2) results in poorer orbital overlap, likely due to significant longitudinal and latitudinal slippage between molecules in the crystal lattice. As a consequence, no field-effect response was observed for the device fabricated from (2).
\end{abstract}

Received 14th August 2014,
Accepted 26th September 2014

DOI: $10.1039 /$ c4ce01686f

www.rsc.org/crystengcomm

\section{Introduction}

Interest in organic field-effect transistors (OFETs), and their applications as the components of organic electronics has grown significantly in recent years. ${ }^{1}$ This is in part fuelled by technological advances in fabrication techniques that have led to solution-based deposition techniques such as spin-coating, printing and stamping that are cheaper, large area deposition methods when compared to the more traditional method of vacuum deposition. ${ }^{2}$ Tetrathiafulvalene (TTF) derivatives have been widely studied as organic conductors and superconductors since their discovery in the 1970 's. ${ }^{3}$ They have a range of chemically and electrochemically accessible, reversible oxidation states and favourable molecular structures with strong intermolecular $\pi-\pi, \mathrm{S} \cdots \mathrm{S}$ and $\mathrm{C}-\mathrm{H} \cdots \mathrm{S}$ interactions that facilitate good charge transport properties. ${ }^{4}$ Within the past two decades, several TTF-donors have been successfully implemented as the active layers of OFET devices ${ }^{5,6}$ and the charge carrier mobilities of such materials have been related

\footnotetext{
${ }^{a}$ Department of Chemistry, Brock University, 500 Glenridge Avenue, ON, L2S 3A1, Canada.E-mail: mpilkington@brocku.ca

${ }^{b}$ School of Science and Technology, Nottingham Trent University, Clifton Lane, Nottingham, NG11 8NS, UK

${ }^{c}$ Xerox Research Centre of Canada, 2660 Speakman Drive, Mississauga, ON, L5K 2L1, Canada

$\dagger$ Electronic supplementary information (ESI) available: Details of the crystallography for 1 and 2. CCDC 1016259-1016260. For ESI and crystallographic data in CIF or other electronic format see DOI: 10.1039/c4ce01686f

\$ Present address. School of Chemistry and Chemical Engineering, Wuhan Textile University, Wuhan, 430073, China.
}

to the crystal structures of their organic donors. ${ }^{7}$ To date mobilities greater than $10 \mathrm{~cm}^{2} \mathrm{~V}^{-1} \mathrm{~s}^{-1}$ have been achieved by functionalizing the TTF core, which is promising for the future of organic microelectronics. ${ }^{4}$ Thiophene-based materials on the other hand are also intensely studied as candidates for organic semiconductors and oligothiophenes, consisting of $\alpha$-linked thiophene units, have been widely applied in the field of OFETs. ${ }^{7-9}$ Interestingly, thiophenefused TTF derivatives with two redox active components have been reported to form parallel stacks of donors that facilitate good charge carrier mobilities. ${ }^{9}$ In addition to a range of stable oxidation states, the tailoring of intra- and intermolecular interactions in both thiophene and TTF-derivatives permits their electronic properties to be fine-tuned at the molecular level. Yet the synthesis of suitable compounds with high solubilities and their incorporation into crystalline thin films with moderate conductivities for OFET devices remains a challenging task that should not be underestimated. Developing new classes of tuneable molecules is an important first step since the self-assembly of these molecules from solution requires a delicate balance between the structure-directing components which favour molecular stacking for transport properties and solubilizing groups which assist solution deposition methods.

Previous research efforts in our group have focused on new synthetic methodologies for the preparation of TTF and BEDT-TTF (BEDT = bis(ethylenedithio)) donors as precursors to molecule-based conducting and/or magnetic materials. ${ }^{10}$ BEDT-TTF derivatives have been much less well explored than their TTF counterparts with just a few reported examples 
of single crystals of charge transfer salts of BEDT-TTF derivatives incorporated into OFET devices. ${ }^{11}$

In this new study we report the synthesis of three new donors comprising ester-linked thiophene groups attached via alkyl linkers to the six-membered dithiin ring of a BEDT-TTF, 1-3. Our objectives are two-fold: i) to exploit the inter- and intramolecular $\mathrm{H}$-bonding, $\pi-\pi$ stacking and $\mathrm{S} \cdots \mathrm{S}$ contacts of two redox active components within a single organic donor in the solid state in order to improve charge carrier mobilities and ii) to evaluate the potential of these compounds as air stable, $p$-type semiconductors for incorporation into organic field-effect transistors (OFETs).

\section{Experimental section}

\section{General considerations}

All experiments were performed under a nitrogen atmosphere unless stated otherwise. Dry solvents were obtained from a Puresolve PS MD-4 solvent purification system. Hydroxyl functionalized BEDT-TTF derivatives were prepared according to procedures published elsewhere. ${ }^{12,13}{ }^{1} \mathrm{H}$ and ${ }^{13} \mathrm{C}$ NMR spectra were recorded in deuterated solvents on Bruker AVANCE AV300 or AV600 NMR spectrometers and chemical shifts were determined with reference to residual solvent. IR spectra were recorded on a Mattson Research Series FT-IR spectrometer as KBr discs. EI and HR FAB mass spectrometery measurements were obtained from a KRATOS/MSI CONCEPT 1-S spectrometer. Elemental analysis (CHN) was obtained from Atlantic Microlab. Melting points were measured on a SMP10 melting point apparatus. Cyclic voltammetry measurements were recorded at room temperature under $\mathrm{N}_{2}$ in a conventional three-electrode cell using Pt working electrodes $(3 \mathrm{~mm}$ diameter), a Pt wire counter electrode, and a $\mathrm{Ag} / \mathrm{AgCl}$ reference electrode using a BAS Epsilon potentiostat. Electronic absorption spectra were measured on a Varian 5000 UV-vis-NIR spectrophotometer. Fabricated OTFT devices were evaluated using a Keithley SCS-4200 characterization system under ambient conditions. Four-probe DC measurements were carried out on a Keithley 236 Source Measurement Unit. Optical microscope images of crystals bridging electrodes were taken with an Olympus DP 10.

Synthesis of (2-thiophenoyl)oxyethyl-BEDT-TTF (1). Triethylamine $(2.5 \mathrm{~mL})$ and 2-thiophenecarbonyl chloride $(0.13 \mathrm{~g}, 0.91 \mathrm{mmol})$ were added to a solution of hydroxyethylBEDT-TTF (HEET) $)^{13 a}(0.30 \mathrm{~g}, 0.70 \mathrm{mmol})$ in dry THF $(20 \mathrm{~mL})$ at $0{ }^{\circ} \mathrm{C}$, and the mixture was stirred at RT for $17 \mathrm{~h}$ under $\mathrm{N}_{2}$. The mixture was filtered, and the filtrate partitioned between $\mathrm{CH}_{2} \mathrm{Cl}_{2}(30 \mathrm{~mL})$ and water $(20 \mathrm{~mL})$. The organic layer was separated, washed with water $(30 \mathrm{~mL})$ and dried over $\mathrm{MgSO}_{4}$. Removal of solvent in vacuo afforded a sticky residue, which was purified by chromatography ( $\mathrm{SiO}_{2}$, hexane : $\left.\mathrm{CH}_{2} \mathrm{Cl}_{2} 1: 1\right)$ to yield 1 as a yellow powder $(0.24 \mathrm{~g}, 64 \%)$, m.p. $116-118{ }^{\circ} \mathrm{C}$. $\delta_{\mathrm{H}}\left(300 \mathrm{MHz}, \mathrm{CDCl}_{3}\right): 7.83\left(\mathrm{dd}, J=0.8,3.6 \mathrm{~Hz}, 1 \mathrm{H}, 3^{\prime \prime}-H\right), 7.60$ (dd, $\left.J=0.8,4.9 \mathrm{~Hz}, 1 \mathrm{H}, 5^{\prime \prime}-H\right), 7.15$ (dd, $\left.J=3.9,4.8 \mathrm{~Hz}, 1 \mathrm{H}, 4^{\prime \prime}-H\right)$, $4.53\left(\mathrm{~m}, 2 \mathrm{H}, \mathrm{OCH}_{2}\right), 3.77(\mathrm{~m}, 1 \mathrm{H}, 5-H), 3.42\left(\mathrm{~m}, 1 \mathrm{H}, 6-H_{\alpha}\right)$, $3.32\left(\mathrm{~s}, 4 \mathrm{H}, 5^{\prime}-6^{\prime}-\mathrm{H}_{2}\right), 3.16\left(\mathrm{~m}, 1 \mathrm{H}, 6-\mathrm{H}_{\beta}\right), 2.27\left(\mathrm{~m}, 2 \mathrm{H}, \mathrm{OCH}_{2} \mathrm{CH}_{2}\right)$;
$\delta_{\mathrm{C}}\left(75 \mathrm{MHz}, \mathrm{CDCl}_{3}\right): 162.06(C=\mathrm{O}), 133.74,133.26,132.71 \&$ $127.93\left(2^{\prime \prime}-, 3^{\prime \prime}-, 4^{\prime \prime}-5 "-C\right), 113.89,112.98,112.89,111.62$ (6 × $\left.\mathrm{sp}^{2} C\right), 61.82\left(\mathrm{OCH}_{2}\right), 40.17(5-C), 35.30\left(\mathrm{OCH}_{2} \mathrm{CH}_{2}\right), 33.93$ (6-C), $30.18\left(5^{\prime}-, 6^{\prime}-C\right) ; v_{\max }\left(\mathrm{cm}^{-1}, \mathrm{KBr}\right): 3089(\mathrm{w}), 2915(\mathrm{w})$, 1692 (s), 1522 (w), 1447 (w), 1418 (m), 1357 (w), 1287 (m), 1264 (s), 1210 (w), 1092 (s), 998 (w), 860 (w), 749 (m), 452 (w); $m / z:$ (FAB) 538 ([M] $\left.]^{+}, 100 \%\right) ; H R M S:$ (FAB) found $[\mathrm{M}]^{+}$ 537.84569, $\mathrm{C}_{17} \mathrm{H}_{14} \mathrm{O}_{2} \mathrm{~S}_{9}$ requires 537.84803. Elem. anal. found C: $38.03, \mathrm{H}: 2.44 \% ; \mathrm{C}_{17} \mathrm{H}_{14} \mathrm{O}_{2} \mathrm{~S}_{9}$ requires C: $37.92, \mathrm{H}: 2.60 \%$. Single crystals of 1 suitable for X-ray crystallography were obtained via the slow diffusion of hexane into a $\mathrm{CH}_{2} \mathrm{Cl}_{2}$ solution of the donor.

Synthesis of (2-thiophenoyl)oxymethyl-BEDT-TTF (2). Triethylamine $(5 \mathrm{~mL}, 36 \mathrm{mmol})$ and 2-thiophenecarbonyl chloride $(0.44 \mathrm{~g}, 3.0 \mathrm{mmol})$ were added to a solution of (hydroxymethyl)BEDT-TTF (HMET) ${ }^{12}(0.65 \mathrm{~g}, 1.57 \mathrm{mmol})$ in dry THF $(30 \mathrm{~mL})$ at $0{ }^{\circ} \mathrm{C}$, and the mixture was stirred at RT for $17 \mathrm{~h}$ under $\mathrm{N}_{2}$. The mixture was filtered, and the filtrate partitioned between $\mathrm{CH}_{2} \mathrm{Cl}_{2}(30 \mathrm{~mL})$ and water $(20 \mathrm{~mL})$. The organic layer was separated, washed with water $(30 \mathrm{~mL})$ and brine $(20 \mathrm{~mL})$ and dried over $\mathrm{MgSO}_{4}$. Removal of solvent in vacuo afforded an orange sticky residue, which was purified by chromatography $\left(\mathrm{SiO}_{2}\right.$, hexane: $\left.\mathrm{CH}_{2} \mathrm{Cl}_{2} 1: 1\right)$ to yield 2 as an orange solid $(0.63 \mathrm{~g}, 77 \%)$, m.p. $151-152{ }^{\circ} \mathrm{C} ; \delta_{\mathrm{H}}$ $\left(300 \mathrm{MHz}, \mathrm{CDCl}_{3}\right.$ ): 7.86 (dd, $\left.J=0.6,3.5 \mathrm{~Hz}, 1 \mathrm{H}, 3^{\prime \prime}-H\right), 7.62$ (dd, $J=0.7,4.9 \mathrm{~Hz}, 1 \mathrm{H}, 5 "-H), 7.15(\mathrm{dd}, J=3.9,4.7 \mathrm{~Hz}, 1 \mathrm{H}$, $\left.4^{\prime \prime}-H\right), 4.57$ (d, $\left.J=8.1 \mathrm{~Hz}, 2 \mathrm{H}, \mathrm{OCH}_{2}\right), 4.05(\mathrm{~m}, 1 \mathrm{H}, 5-H), 3.32$ $\left(\mathrm{s}, 4 \mathrm{H}, 5^{\prime}-, 6^{\prime}-H_{2}\right), 3.28\left(\mathrm{~m}, 6-H_{2}\right) ; \delta_{\mathrm{C}}\left(75 \mathrm{MHz}, \mathrm{CDCl}_{3}\right): 161.77$ $(C=\mathrm{O}), 134.15,133.15,132.63,127.98$ (2"-, $\left.3^{\prime \prime}-, 4^{\prime \prime}-, 5^{\prime \prime}-C\right), 113.95$, 113.92, 113.86, $112.57 \& 111.20\left(6 \times \mathrm{sp}^{2} \mathrm{C}\right), 65.14\left(\mathrm{CH}_{2} \mathrm{O}\right), 42.16$ (5-C), 32.39 (6-C), $30.40\left(5^{\prime}-, 6^{\prime}-C\right) ; v_{\max }\left(\mathrm{cm}^{-1}, \mathrm{KBr}\right): 3087(\mathrm{w})$, 2952 (w), 2917 (w), 1708 (vs), 1518 (w), 1446 (w), 1412 (m), 1256 (vs), 1221 (m), 1098 (s), 1040 (w), 902 (w), 857 (w), 771 (w), $744(\mathrm{w}), 722(\mathrm{~m}), 503(\mathrm{w}), 452(\mathrm{w}) ; \mathrm{m} / \mathrm{z}$ : (FAB) $524\left([\mathrm{M}]^{+}, 100 \%\right)$; HRMS: (FAB) found $[\mathrm{M}]^{+} 523.82639, \mathrm{C}_{16} \mathrm{H}_{12} \mathrm{O}_{2} \mathrm{~S}_{9}$ requires 523.83238. Elem. anal. found C: $35.22, \mathrm{H}: 2.20 \% ; \mathrm{C}_{16} \mathrm{H}_{12} \mathrm{O}_{2} \mathrm{~S}_{9} \cdot \mathrm{H}_{2} \mathrm{O}$ requires C: $35.42, \mathrm{H}: 2.58 \%$. Single crystals of 2 suitable for $\mathrm{X}$-ray crystallography were grown from the slow diffusion of hexane into a $\mathrm{CH}_{2} \mathrm{Cl}_{2}$ solution of the donor.

Synthesis of cis-bis(2-thiophenoyloxymethyl)-BEDT-TTF (3). Triethylamine $(9 \mathrm{~mL}, 65 \mathrm{mmol})$ and 2-thiophenecarbonyl chloride $(0.81 \mathrm{~g}, 5.50 \mathrm{mmol})$ were added to a solution of cis-5,6-(dihydroxymethyl)BEDT-TTF ${ }^{13 b}(0.62 \mathrm{~g}, 1.40 \mathrm{mmol})$ in dry THF $(30 \mathrm{~mL})$ at $0{ }^{\circ} \mathrm{C}$, and the mixture stirred at RT for $15 \mathrm{~h}$ under $\mathrm{N}_{2}$. The bright yellow precipitate was collected by filtration, and washed with water and then $\mathrm{MeOH}$, and dried in vacuo to afford 3 as a bright yellow solid $(0.83 \mathrm{~g}, 89 \%), \mathrm{m}$. p. $199-202{ }^{\circ} \mathrm{C}$ (dec.). $\delta_{\mathrm{H}}\left(600 \mathrm{MHz}, \mathrm{CDCl}_{3}\right): 7.80(\mathrm{dd}, J=0.9$, $\left.3.6 \mathrm{~Hz}, 2 \mathrm{H}, 2 \times 3^{\prime \prime}-\mathrm{H}\right), 7.66$ (dd, $\left.J=0.9,4.8 \mathrm{~Hz}, 2 \mathrm{H}, 2 \times 5^{\prime \prime}-\mathrm{H}\right)$, $7.16\left(\mathrm{dd}, J=3.6,4.8 \mathrm{~Hz}, 2 \mathrm{H}, 2 \times 4^{\prime \prime}-\mathrm{H}\right), 4.68(\mathrm{~m}, 4 \mathrm{H}, 2 \times$ $\left.\mathrm{CH}_{2} \mathrm{O}\right), 4.20(\mathrm{~m}, 2 \mathrm{H}, 5-, 6-\mathrm{H}), 3.34\left(\mathrm{~s}, 4 \mathrm{H}, 5^{\prime}-, 6^{\prime}-\mathrm{H}_{2}\right) ; \delta_{\mathrm{C}}$ (150 MHz): $161.39(2 \times C=\mathrm{O}), 134.21,133.32,132.44 \& 127.99$ $\left(2 \times 2 "-, 3^{\prime \prime}-, 4^{\prime \prime}-, 5\right.$ "-C), 113.93, 113.87, $111.48\left(6 \times \mathrm{sp}^{2}-C\right), 64.08$ $\left(2 \times \mathrm{CH}_{2} \mathrm{O}\right), 43.95(5-, 6-C), 30.19$ (5'-, $\left.6^{\prime}-\mathrm{C}\right) ; v_{\max }\left(\mathrm{cm}^{-1}, \mathrm{KBr}\right):$ 3095 (w), 2953 (w), 2917 (w), 1703 (vs), 1519 (m), 1456 (w), 1413 (s), 1382 (w), 1354 (m), 1255 (vs), 1223 (m), 1098 (vs), 
$1041(\mathrm{~m}), 909(\mathrm{w}), 860(\mathrm{~m}), 820(\mathrm{w}), 773(\mathrm{w}), 746(\mathrm{~m}), 721(\mathrm{~m})$, $490(\mathrm{w}), 432(\mathrm{w}) ; \mathrm{m} / \mathrm{z}$ : (FAB) $664\left([\mathrm{M}]^{+}, 15 \%\right) ; H R M S$ : (FAB) found $[\mathrm{M}]^{+} 663.82675, \mathrm{C}_{22} \mathrm{H}_{16} \mathrm{O}_{4} \mathrm{~S}_{10}$ requires 663.82559. Elem. anal. found C: $37.64, \mathrm{H}: 2.44 \% ; \mathrm{C}_{22} \mathrm{H}_{16} \mathrm{O}_{4} \mathrm{~S}_{10} \cdot 2 \mathrm{H}_{2} \mathrm{O}$ requires C: 37.71, H: $2.86 \%$.

$\mathrm{X}$-ray structure determination. Single crystals of 1 and 2 were mounted on a cryoloop with paratone oil and examined on a Bruker APEX-II CCD diffractometer equipped with an Oxford Cryoflex low temperature device. Data were measured at $150(2) \mathrm{K}$ using graphite-monochromated Mo-K $\alpha$ radiation $(\lambda=0.71073 \AA)$ and the APEX-II software. ${ }^{14}$ Final cell constants were determined from full least squares refinement of all observed reflections. The data were corrected for absorption (SADABS). ${ }^{15}$ Cell refinement and data-reduction were carried out by SAINT. ${ }^{15}$ For both compounds, the structures were solved by direct methods (SHELXS-97) and refined with full least squares refinement on $F^{2}$ using SHELXL-97 within the Bruker SHELXTL suite. ${ }^{16}$ The structure of 1 exhibited disorder in the thiophene ring that was modelled over two sites. Hydrogen atoms were placed at calculated positions and refined isotropically with a riding model using SHELXTL default parameters. Crystallographic parameters for $\mathbf{1}$ and $\mathbf{2}$ are summarized in Table 1 . Selected bond lengths and angles are provided in the ESI $\dagger$ (S-2 and S-3). The structures have been allocated the following CCDC deposition numbers CCDC 1016259-1016260.

\section{Computational studies}

MO calculations were carried out on 1 and 2 with DFT methods. Initial geometry optimizations were undertaken using the Pople ${ }^{17} 6-31 G^{*+}$ basis set and B3LYP1 functional

Table 1 Crystallographic data for 1 and 2

\begin{tabular}{lll}
\hline Complex & 1 & 2 \\
\hline Formula & $\mathrm{C}_{17} \mathrm{H}_{14} \mathrm{O}_{2} \mathrm{~S}_{9}$ & $\mathrm{C}_{16} \mathrm{H}_{12} \mathrm{O}_{2} \mathrm{~S}_{9}$ \\
Formula mass & 538.82 & 524.80 \\
Crystal system & Monoclinic & Triclinic \\
Crystal size & $0.31 \times 0.30 \times 0.12$ & $0.54 \times 0.30 \times 0.04$ \\
Description & Block & Plate \\
Crystal colour & Yellow & Orange \\
Space group & $C 2 / c$ & $P \overline{1}$ \\
$a / \AA$ & $37.3030(17)$ & $6.5563(5)$ \\
$b / \AA$ & $8.94339(4)$ & $9.9629(8)$ \\
$c / \AA$ & $12.9131(11)$ & $16.1326(13)$ \\
$\alpha /{ }^{\circ}$ & 90 & $105.019(2)$ \\
$\beta / \circ$ & $100.327(2)$ & $96.449(2)$ \\
$\gamma /{ }^{\circ}$ & 90 & $97.549(2)$ \\
$V\left(\AA^{3}\right)$ & $4243.3(3)$ & $997.10(14)$ \\
Temp./K & $150(2)$ & $150(2)$ \\
$Z$ & 8 & 2 \\
Reflns collected & 29144 & 28983 \\
Unique reflns & 5284 & 4916 \\
$R_{\text {int }}$ & 0.0287 & 0.0334 \\
$R_{1}(I>2 \sigma(I))$ & 0.0530 & 0.0357 \\
w $R_{2}(I>2 \sigma(I))$ & 0.1198 & 0.0793 \\
Final $R_{1}$ values (all data) & 0.0547 & 0.0390 \\
Final w $R_{2}($ all data) & 0.1208 & 0.0830 \\
Number of parameters & 246 & 244 \\
& &
\end{tabular}

within Jaguar. ${ }^{18}$ Subsequent single-point energy calculations were performed on the optimized structure using the larger triple zeta 6-311G-3DF-3PD basis set. ${ }^{19}$

\section{Thin film preparation}

Polystyrene films comprising (donor) $)_{x}$-(polyiodides) $y$ on a Si wafer ${ }^{20,21}$. A polymer blend thin-film containing 1:1 weight ratio of donor/PS on a Si wafer substrate was prepared by spin coating a $1 \mathrm{wt} \%$ solution of donor/PS (1:1 weight ratio) in chlorobenzene at $1000 \mathrm{rpm}$ for $45 \mathrm{~s}$. The film was dried in a vacuum oven at $65^{\circ} \mathrm{C}$ for $3 \mathrm{~h}$ to remove any solvent residue and then deposited with $\mathrm{Au}$ electrodes. The film was then doped with iodine vapour from an $\mathrm{I}_{2} / \mathrm{CH}_{2} \mathrm{Cl}_{2}(100 \mathrm{mg}$ $20 \mathrm{~mL}^{-1}$ ) solution for $8 \mathrm{~min}$ at RT.

Polystyrene films comprising (donor) $)_{x}$-(polyiodides) $y$ on a

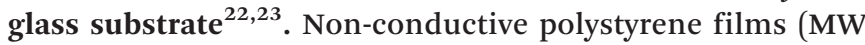
$45000)(20 \mu \mathrm{m}$ thickness) on glass substrate containing a $5 \mathrm{wt} \%$ of molecularly dispersed donor in a polystyrene matrix were obtained by casting from a solution of PS polymer and BEDT-TTF derivative in $o$-dichlorobenezene at $120{ }^{\circ} \mathrm{C}$. The films were then exposed to iodine vapour from an $\mathrm{I}_{2}-\mathrm{CH}_{2} \mathrm{Cl}_{2}$ solution $\left(0.1 \mathrm{~g} 20 \mathrm{~mL}^{-1}\right)$ for $8 \mathrm{~min}$. Such treatment resulted in the formation of a continuous network containing (donor) $)_{x}$-(polyiodides) $)_{y}$ in a surface layer of the polystyrene film. The weight percentage of donor relative to PS was then varied from 5 to 10 and then $20 \mathrm{wt} \%$ and the above procedure repeated to prepare a range of doped thin films.

\section{OFET device fabrication and evaluation}

The fabrication of the device was accomplished at ambient conditions without taking any precautions to isolate the material and device from exposure to ambient oxygen, moisture, or light. Experimental bottom-gate thin film transistor (TFT) devices were built onto an $n$-doped silicon wafer as the gate electrode with a $100 \mathrm{~nm}$ thermal $\mathrm{SiO}_{2}$ as the dielectric layer, with or without an octyltrichlorosilane (OTS) modified monolayer. The performances were measured in a topcontact configuration (drain and source electrodes deposited above the semiconductor). Gold source and drain contacts were deposited onto the organic layer through a shadow mask. The OFET characteristics of the devices were determined at room temperature in air using a Keithley 4200 SCS semiconductor characterization system under ambient conditions. The field-effect mobility $\mu$ for 1 , was calculated from the data in the saturated regime according to eqn (1): ${ }^{24}$

$$
I_{\mathrm{SD}}=C_{\mathrm{i}} \mu(W / 2 L)\left(V_{\mathrm{G}}-V_{\mathrm{T}}\right)^{2}
$$

where $I_{\mathrm{SD}}$ is the source drain current at the saturated regime; $W$ and $L$ are the width and length of the semiconductor channel, $C_{\mathrm{i}}$ is the capacitance per unit area of the gate $\mathrm{SiO}_{2}$ dielectric layer, and $V_{\mathrm{G}}$ and $V_{\mathrm{T}}$ are the gate and threshold voltages. The $V_{\mathrm{T}}$ of the device was determined from the relationship between the square root of $I_{\mathrm{SD}}$ at the saturated regime and $V_{\mathrm{G}}$ of the device by extrapolating the measured data to $I_{\mathrm{SD}}=0$. 


\section{Results and discussion}

Synthetic procedures

BEDT-TTF derivatives 1-3 containing thiophene groups (Fig. 1) were prepared in good yields by reaction of the appropriate hydroxyl donor ${ }^{12,13}$ with 2-thiophenecarbonyl chloride in the presence of triethylamine. All three donors were fully characterized by ${ }^{1} \mathrm{H}$-and ${ }^{13} \mathrm{C}$-NMR and IR spectroscopy, FAB mass spectrometry, as well as elemental analysis. X-ray quality single crystals of 3 could not be obtained due to its poor solubility in common organic solvents. Moreover its poor solubility precluded thin film and device fabrication studies, hence this compound was abandoned at this early stage. In contrast, both 1 and 2 proved more soluble in a range of organic solvents and single crystals were grown from a $\mathrm{CH}_{2} \mathrm{Cl}_{2}$ solution via hexane diffusion.

\section{X-ray crystallography}

Neutral donors 1 and 2 were characterized by X-ray diffraction. Crystallographic data for donors 1 and 2 are summarized in Table 1 . Donor 1 crystallizes in the monoclinic space group $C 2 / c$ with one unique molecule in the asymmetric unit (Fig. 2). There is 50:50 disorder of two orientations of the thiophene ring in the molecule that are related by a twist of ca. $180^{\circ}$ about the thiophene-acyl bond. The organosulfur donor is strongly distorted into a curved structure due to bends about the dithiole $S \cdots S$ vectors of $36.5^{\circ}$ at the unsubstituted end, and $22.7^{\circ}$ at the substituted end of the molecule (Fig. 3). The side chain is attached at the pseudo axial position of the methylene bridge of the organosulfur donor with its $\mathrm{CH}_{2}-\mathrm{CH}_{2}$ bond adopting a gauche conformation. The donor molecules are organized into centrosymmetric pairs in which the substituted dithiolo-dithiin rings lie opposite each other to give the head-to-tail arrangement shown in (Fig. 3), though the $S \cdots S$ distances between them are longer than the sum of their van der Waals radii, with $d_{\mathrm{S} 8 \cdots \mathrm{S} 5}=4.058(1)$ and $d_{\mathrm{S} 6 \cdots \mathrm{S} 7}=3.851(1) \AA$.

This arrangement results in a pair of soft, $S \cdots A r$ interactions, $d_{\mathrm{S} 2 \cdots \mathrm{C} 15}=3.447 \AA$ involving the first orientation of the thiophene ring and two $\mathrm{CH} \cdots \mathrm{S}$ interactions $\left(d_{\text {s9A-H11A }}=2.704 \AA\right.$ and $d_{9 \mathrm{~A}-1 \mathrm{~A}}=3.000 \AA$ ) involving the second orientation, as well as two sets of intermolecular interactions between the axial

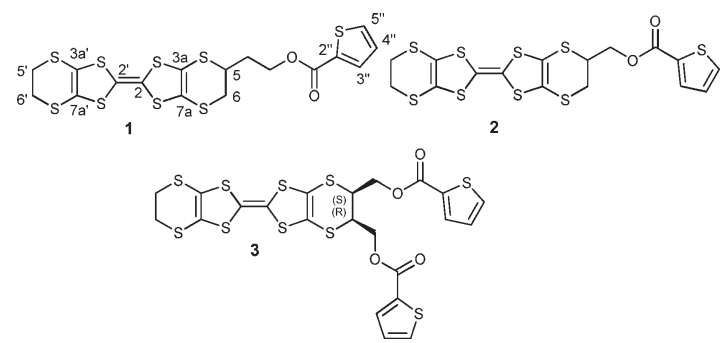

Fig. 1 Molecular structures of the thiophene appended BEDT-TTF derivatives (1-3). The atomic numbering scheme used to assign the ${ }^{1} \mathrm{H}$ and ${ }^{13} \mathrm{C}$ NMR data is given on donor 1 .

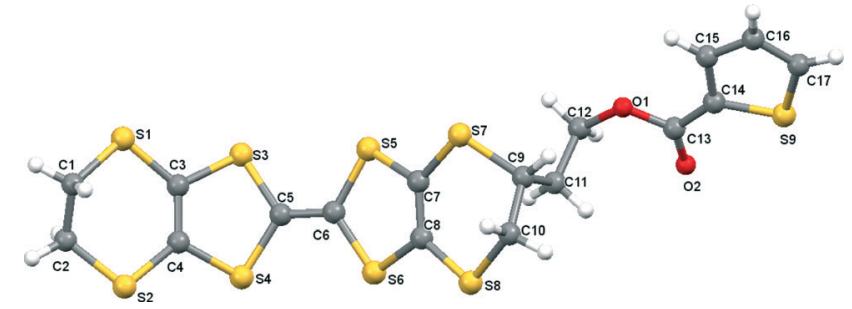

Fig. 2 Representation of the molecular structure of 1 with the atomic labeling scheme. Only one orientation of the thiophene ring is presented.
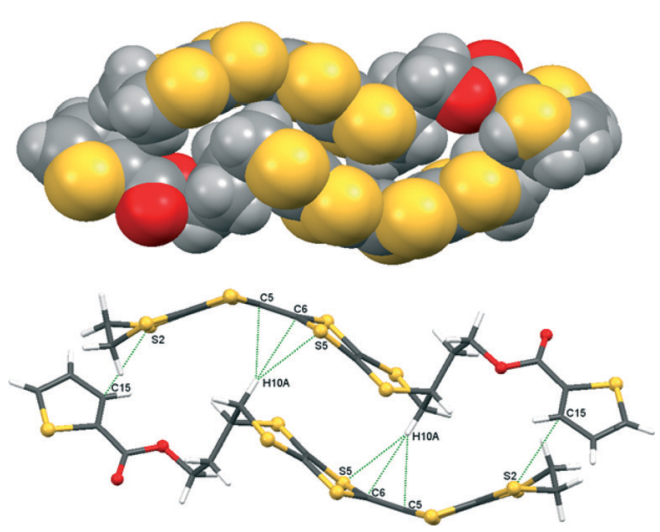

Fig. 3 Top, space filling model showing the head to tail arrangement of donors in a dimer; bottom, centrosymmetric pairs of 1 stabilized by a soft $\mathrm{S} \cdots \mathrm{Ar}$ as well as $\mathrm{C}-\mathrm{H} \cdots \pi$ and $\mathrm{C}-\mathrm{H} \cdots \mathrm{S}$ interactions shown as dashed green lines.

$\mathrm{C}-\mathrm{H}$ from a substituted dithiin ring with the central $\pi$-bond and a sulfur atom of the other donor such that $d_{\mathrm{H} 10 \mathrm{~A} \cdots \mathrm{C} 5}=$ $2.628 \AA, d_{10 \mathrm{HA}{ }^{\cdots \mathrm{C} 6}}=2.593 \AA$ and $d_{10 \mathrm{~A} \cdots \mathrm{S} 5}=2.953 \AA$. Pronounced curvature is not unusual for a neutral BEDT-TTF donor core that is quite flexible, unlike in its oxidized state where it adopts a close to planar configuration. This type of curvature has been observed previously in the crystal structure of enantiopure bis(pentane-2,4-dithio) $\mathrm{TTF}^{25}$ and for a capsulelike structure assembled from six BEDT-TTF derivatives. ${ }^{26}$ There are short $\mathrm{S} \cdots \mathrm{S}$ contacts that link neighbouring donor molecules in three-dimensions throughout the crystal lattice. The best planes defined by the central four sulfur atoms of each donor are only $3.246 \AA$ apart, with shortest $S \cdots S$ contacts between S5 and S6 of neighbouring molecules of 3.495(1) $\AA$ (Fig. 4). These pairs are stacked along the $b$-axis of the unit cell (Fig. 5). In order to accommodate the thiophene-containing side-chain, the two donors that form a dimer pair are offset with respect to each other (Fig. 5, bottom).

Additional stacks lie end-to-end in the $a$-direction. There are $S \cdots S$ contacts between neighbouring stacks in the $b$ - and $c$-directions, for which the shortest $\mathrm{S} \cdots \mathrm{S}$ contacts are $d_{\mathrm{S} 7 \cdots \mathrm{S} 7}=$ $3.519(1) \AA$ and $d_{\mathrm{S} 4 \cdots \mathrm{S} 6}=3.561(1)$ Å respectively (Fig. 4).

Donor 2 crystallizes in the triclinic space group $P \overline{1}$ with one unique molecule in the asymmetric unit. The crystal structure reveals that the molecule has a more planar structure when compared to 1, with flexings about the dithiole $\mathrm{S} \cdots \mathrm{S}$ vectors of only 7.2 and $13.6^{\circ}$. The side arm adopts an 


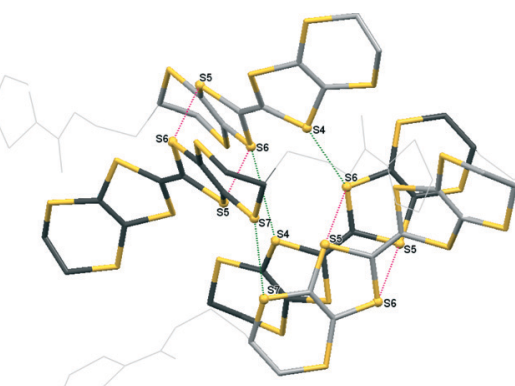

Fig. 4 Crystal packing of 1; showing the longitudinal S $\cdots S$ contacts between pairs of dimers (red dashed lines) and lateral, inter-dimer $\mathrm{S} \cdots \mathrm{S}$ contacts (green dashed lines). $\mathrm{H}$-atoms are omitted for clarity.

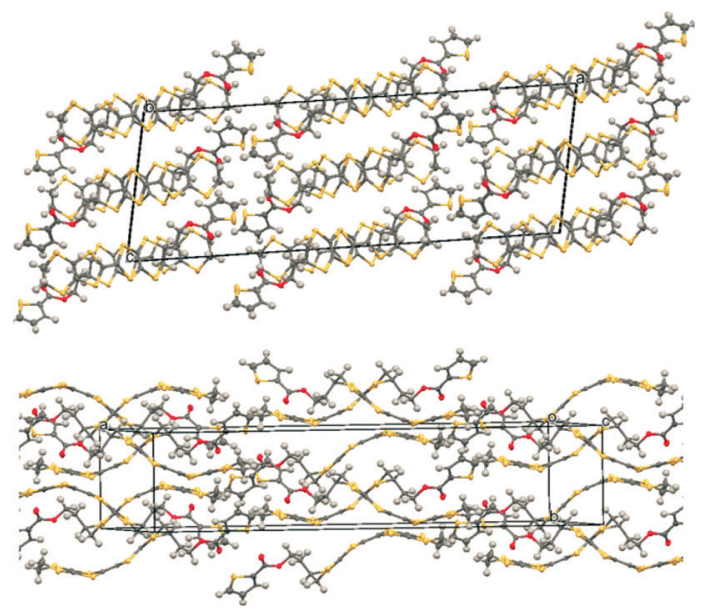

Fig. 5 Crystal packing of 1 . Top, view down the $b$-axis showing pairs of centrosymmetrically related dimers stacking in a head-to-tail fashion. Bottom, view highlighting the pronounced curvature of the BEDTTTF derivatives and the space in the crystal lattice that accommodates the thiophene side chains.

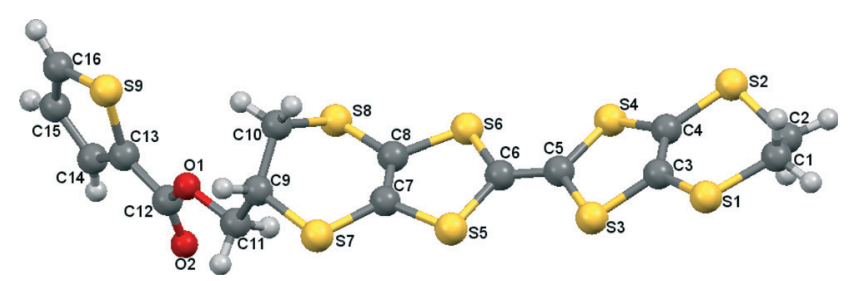

Fig. 6 Representation of the molecular structure of 2 with the atomic labeling scheme.

extended conformation attached to the pseudo-axial position of the 1,4-dithiin ring (Fig. 6).

In contrast to the packing arrangement of 1 ; molecules of 2 are arranged in a side-by-side manner with short $S \cdots S$ contacts along the $a$-direction of the unit cell. Each donor forms a centrosymmetric dimer with a molecule from an adjacent row, but the two molecules are significantly offset to the side from each other (Fig. 7).

The $S \cdots \mathrm{S}$ contacts in the $a$-direction $\left(d_{\mathrm{S} 7 \cdots \mathrm{S} 8}=3.3548(8)\right.$, $\left.d_{\mathrm{S} 5 \cdots \mathrm{s} 8}=3.3819(7), d_{\mathrm{S} 1 \cdots \mathrm{s} 2}=3.4502(9) \AA\right)$ are mostly shorter than those between offset centrosymmetric pairs $\left(d_{\mathrm{S} 4 \cdots \mathrm{S} 6}=\right.$ $3.5264(9), d_{\mathrm{S} 6 \cdots_{\mathrm{S} 6}}=3.5264(9)$ and $\left.d_{\mathrm{S} 1 \cdots_{\mathrm{S} 4}}=3.5604(8) \AA\right)$,

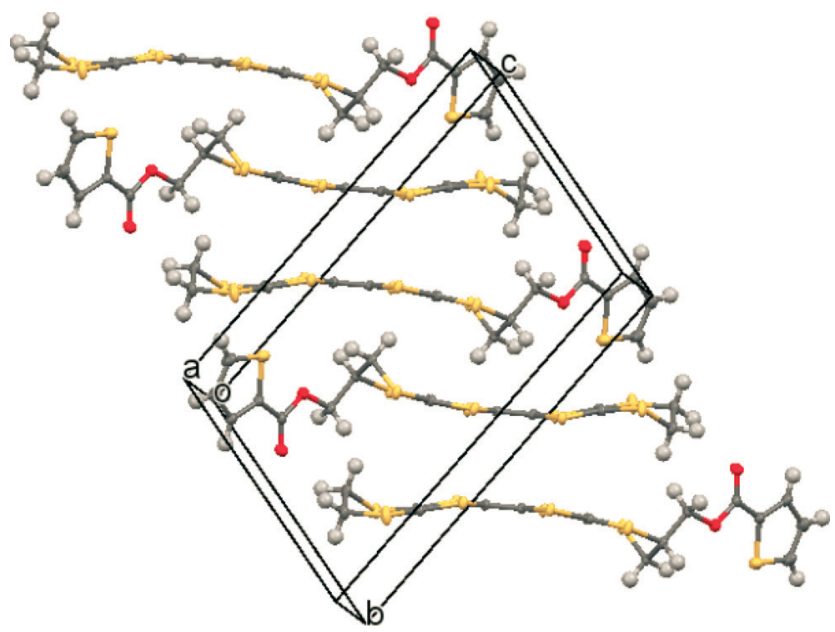

Fig. 7 Packing diagram for 2 showing the relative orientation along the $b$-axis of the offset rows of dimers which are directed along the a-axis.

(Fig. 8). There are no significant $\mathrm{H}$-bonding interactions in the crystal packing of 2 .

A comparison of the crystal structures of 1 and 2 reveals the BEDT-TTF derivatives pack as dimers with lateral $S \cdots S$ contacts in both cases. A study by Rovira et al. of TTF derivatives for OFETs highlights that the supramolecular organization of the donors into chains stabilized via lateral $\mathrm{S} \cdots \mathrm{S}$ interactions is a suitable crystal packing arrangement for good charge carrier mobilities in OFETs. ${ }^{9}$ For the two neutral donors, the longer, evenly spaced $\left(\mathrm{CH}_{2}\right)_{n}$ side chain $(n=2)$ in 1 results in no longitudinal slippage with $\Phi_{1}$ angles all close to $90^{\circ}$, Fig. 9. The degree of latitudinal slippage however is significant with $\Phi_{2}$ angles of $43^{\circ}$ and $59^{\circ}$ between neighbouring donors which reduces the orbital overlap. The distances between the two centroids of the neighbouring 1,4-dithiine rings in 1 are in the range of 4.349-4.713 $\AA$, too long to be considered as $\pi-\pi$ interactions. For donor 2 with the shorter $\mathrm{CH}_{2}$ linker, both the longitudinal and latitudinal slippage angles deviate considerably from $90^{\circ}$, with $\Phi_{1}=31^{\circ}$ and $55^{\circ}$ and $\Phi_{2}=31$ and $54^{\circ}$, indicating that the degree of orbital overlap is poor which could significantly reduce the strength of any $\pi-\pi$ interactions and compromise the electron transport properties of the oxidized donors after doping (vide infra). This is also reflected in the centroid-to-centroid distances between the closest 1,4-dithiin rings of 2 which are in

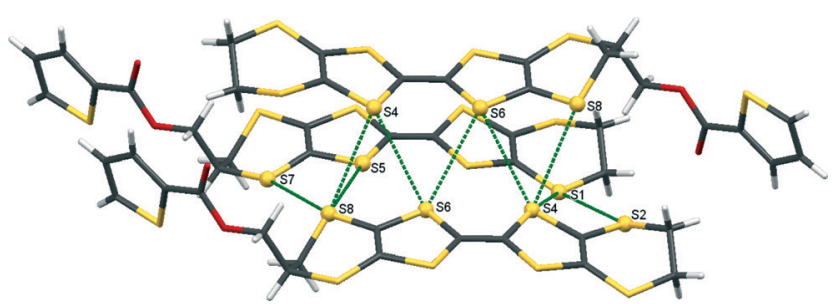

Fig. 8 Crystal packing of 2, showing the relation of a molecule to its neighbours in the next dimer along $a$ and $b$ axes; $S \cdots S$ contacts are shown as green dashed lines. 

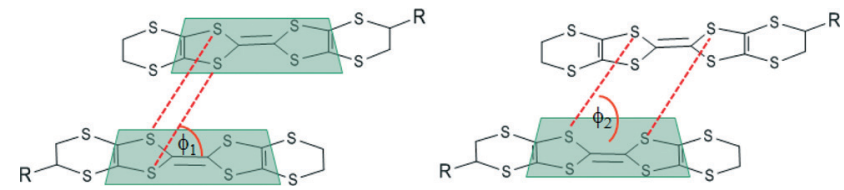

Fig. 9 Angles $\phi_{1}$ and $\phi_{2}$ used to evaluate the degree of longitudinal and latitudinal slippage between neighbouring BEDT-TTF derivatives within a stack.

the range of 5.292 to $5.614 \AA$, approximately $1 \AA$ longer than those previously discussed for 1 . The larger degree of slippage observed for this donor is due to the need to accommodate the thiophene substituent which requires more space due to its shorter, less flexible $\mathrm{CH}_{2}$ linker.

\section{Electrochemical properties}

The redox potentials of 1-3 were investigated by cyclic voltammetry. The results are summarized in Table 2 . All three donors show two reversible single-electron redox processes corresponding to the formation of the radical cation and dication respectively at similar potentials to the unsubstituted BEDT-TTF donor. The cyclic voltammograms for the thiophene donors 1-3 are presented in Fig. 10. The $\mathrm{CV}$ curves were referenced to a $\mathrm{Ag} / \mathrm{AgCl}$ reference electrode.

The calculated HOMO densities of $\mathbf{1}$ and 2 are similar. The HOMO density is high on the sulfur atoms of the TTF core, but negligible on the sulfur atoms of the thiophene rings (Fig. 11). In this respect, although intermolecular interactions from both the TTF and thiophene rings contribute to the crystal packing, it is the short contacts between adjacent TTF donors that are crucial for good charge carrier mobilities and so the electronic properties of $\mathbf{1}$ should not be significantly affected by the positional disorder of the thiophene rings.

\section{Thin film studies}

The good solubilities of thiophene-functionalized donors 1 and 2 in conventional organic solvents permitted the preparation of polymer-blend thin films via spin coating techniques (see ESI $\dagger$ ). ${ }^{1 b}$ The films were then doped with iodine vapor from an $\mathrm{I}_{2} / \mathrm{CH}_{2} \mathrm{Cl}_{2}$ solution. Compared to devices incorporating single crystals, conducting networks formed within a surface layer of a polymer blend offer additional advantages that include higher stabilities, flexibilities and lower densities. FET characterization of doped films comprising of a $1: 1$ weight ratio of 1 or 2 relative to polystyrene (PS) deposited on an unmodified silica wafer substrate showed $I_{\mathrm{DS}}-V_{\mathrm{DS}}$ curves

Table 2 Redox potentials of TTF derivatives vs. $\mathrm{Ag} / \mathrm{AgCl}$ measured in $\mathrm{CH}_{2} \mathrm{Cl}_{2}$

\begin{tabular}{lll}
\hline & $E_{1 / 2}^{1} / \mathrm{V}$ & $E_{1 / 2}^{1} / \mathrm{V}$ \\
\hline BEDT-TTF & 0.48 & 0.89 \\
1 & 0.51 & 0.91 \\
2 & 0.53 & 0.93 \\
3 & 0.55 & 0.95
\end{tabular}

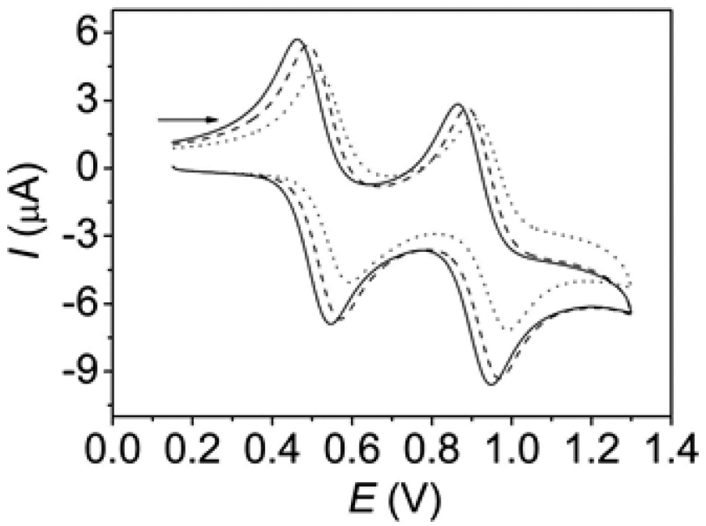

Fig. 10 Cyclic voltammogram for 1 (solid line), 2 (dashed line) and 3 (dotted line) $\left(0.5 \mathrm{mM}\right.$ donor and $0.1 \mathrm{M} \mathrm{Bu}_{4} \mathrm{NPF}_{4}$ in $\mathrm{CH}_{2} \mathrm{Cl}_{2}$ at scan rate $100 \mathrm{mV} \mathrm{s}^{-1}$.

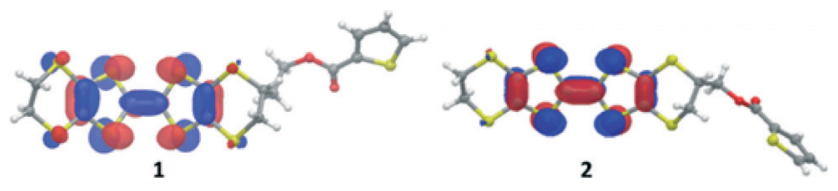

Fig. 11 The HOMO coefficients on 1 and 2 (DFT B3LYP/6-31G(d)) (see ESI $\dagger$ ).

of ohmic and linear properties consistent with quasiconducting behaviour and all the $I-V$ curves overlapped with each other when the gate voltage was changed from 10 to $-40 \mathrm{~V}$ in $10 \mathrm{~V}$ intervals (Fig. 12). For both compounds, the thickness of the films was approximately $27 \mathrm{~nm}$ (vide infra). The specific conductivity for the doped film of $1 / \mathrm{PS}$ was determined to be $1 \times 10^{-5} \mathrm{~S} \mathrm{~cm}^{-1}$. As expected, the un-doped film displayed a lower specific conductivity of $5.6 \times 10^{-7} \mathrm{~S} \mathrm{~cm}^{-1}$. The plot in Fig. 12(c) reveals that $\mathrm{I}_{2}$-doped films of 2/PS exhibit a similar $I-V$ profile to 1 , showing ohmic and linear properties in the measured $V_{\mathrm{DS}}$ range between 0 and $-40 \mathrm{~V}$, along with the gate voltage $V_{\mathrm{G}}$ changing from 10 to $-40 \mathrm{~V}$ in sequence.

The specific conductivity of the doped film of $2 / \mathrm{PS}$ was measured to be $3.5 \times 10^{-5} \mathrm{~S} \mathrm{~cm}^{-1}$, the same order of magnitude as doped 1/PS. The un-doped film of 2 gave rise to the $I_{\mathrm{DS}}-V_{\mathrm{DS}}$ profile shown in Fig. 11(d), consistent with an insulating material. It should be pointed out that the actual thickness of the conducting layer might be much smaller than the polymer film thickness. For example, for a $10 \mu \mathrm{m}$ polycarbonate film containing $2 \mathrm{wt} \%$ BEDT-TTF, the conducting layer of (BEDT-TTF $)_{2} \mathrm{I}_{3}$ formed from iodine vapor doping was estimated to be $140 \mathrm{~nm} .{ }^{20 b}$ Therefore, it is quite possible that the above iodine doped polymer composite films have conductivities higher than recorded. Unfortunately, donor 3 was not sufficiently soluble in organic solvents for thin film fabrication.

In order to further study the electronic properties of the polymer blend thin-films by Vis-NIR spectroscopy, surface conducting polystyrene (PS) films of stoichiometry (donor) $)_{x}$-(polyiodides) $)_{y}$ deposited on a glass substrate were 

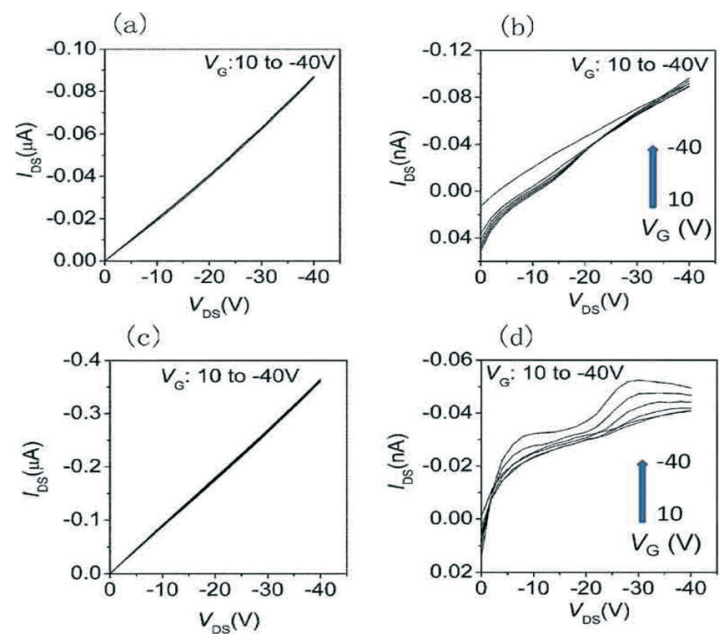

Fig. 12 Drain current versus drain voltage as a function of gate voltage for devices based on (1:1) donor/PS blend films on unmodified $\mathrm{Si}$ wafer substrates at room temperature. (a) $\mathrm{I}_{2}$-doped 1/PS film; (b) undoped 1/PS film; (c) $I_{2}$-doped 2/PS film; (d) undoped 2/PS film. (The gate voltage was changed from 10 to $-40 \mathrm{~V}$ in $10 \mathrm{~V}$ intervals).

prepared from donors 1 and 2, applying a two-step reticulate doping technique following the literature methods reported for similar families of organosulfur donors. ${ }^{20 d, 22,23}$ In contrast to the previous thin film study, the wt\% of donor in the PS composite was varied. It should be noted that since the real thickness of the conducting layer is unknown, the exact resistivity and specific conductivity of the network cannot not be determined and in contrast to the films deposited onto silica wafers, this solution casting method afforded thicker films. Un-doped samples of 1 and 2 exhibited insulating behaviour with conductivities comparable to the glass substrate. Initially, doped films of 1/PS and 2/PS were also insulators however, when the content ratio of 1 was increased in the polymer composite, the doped film showed an increase in conductivity. In this respect, a doped film of $20 \mathrm{wt} \%$ of 1/PS showed a conductivity of $3.7 \times 10^{-3} \mathrm{~S} \mathrm{~cm}^{-1}$ (calculated using the film thickness $20 \mu \mathrm{m}$ as the conducting layer thickness), which is about $10^{4}$ times higher than the $5 \mathrm{wt} \%$ composite. The $I_{\mathrm{DS}}-V_{\mathrm{DS}}$ plots in Fig. 12 also reveal that the conductivity of doped donor/PS (1:1) polymer films on a Si-wafer decreases in the order of $2>1$, which is consistent with results measured for the doped films deposited on the glass substrate.

A comparison of Vis-NIR spectra for a doped film of $\mathbf{1}$, when the wt\% of 1 in polystyrene was varied before doping, is shown in (Fig. 13). The spectrum of the doped polymer of $5 \mathrm{wt} \%$ donor composite shows no absorption bands corresponding to mixed-valence charge transfer (CT) states of the organosulfur donors, while the broad absorption band in the region 1250-1500 $\mathrm{nm}$ is attributed to a charge transfer between fully ionized donor molecules in the insulating layer. ${ }^{27}$ When the ratio of donor 1 is increased to 10 and $20 \mathrm{wt} \%$ respectively, new bands at $\lambda=940$ and $3000 \mathrm{~nm}$ emerge assigned to mixed-valence CT states that are consistent with the increase in conductivity. ${ }^{28}$ The growth of the low-energy band corresponding to intra-band or inter-site

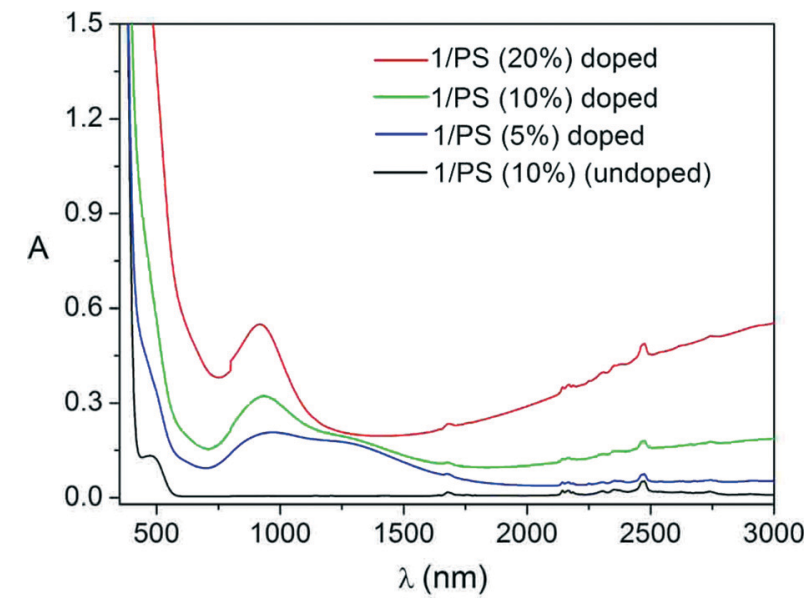

Fig. 13 Vis-NIR spectra of un-doped and doped films on glass substrates for 1/PS with different wt\% ratios of 1 relative to PS.

transitions may in part be attributed to the construction of a $\pi$-conducting network with increasing the donor ratio. It is also likely that in the case of the $5 \mathrm{wt} \%$ doped polymer composite, the smaller amount of the donor is all consumed by iodine and becomes fully oxidized. As the percentage ratio of donor $\mathbf{1}$ is increased, the concentration of fully oxidised salts in the polymer matrix decreases, while the mixed-valence CT salts become dominant in the polymer film. ${ }^{27}$

\section{OFET characteristics}

Thin films (40-60 nm) of 1 and 2 were prepared by spin coating a $1 \mathrm{wt} \%$ of a chlorobenzene solution onto both octyltrichlorosilane (OTS) modified and unmodified substrates. ${ }^{1 b}$ Unfortunately, films deposited on OTS-modified substrates were of poor quality. However a thin film of 1 deposited on unmodified substrate afforded long, thin dendritic crystals during the drying process in vacuo at $60^{\circ} \mathrm{C}$. The performances of the thin films of 1 and 2 were measured in a top-contact configuration with $\mathrm{Au}$ electrodes. An image of one of the measured crystals of 1 lying across two gold electrodes is shown in Fig. 14.

The output and transfer characteristics of the device based on 1 is shown in Fig. 15. The film exhibits negative amplification and performs as a $p$-type transistor with a well-defined linear saturation regime, i.e. when a more negative $V_{\mathrm{G}}$ is applied; more holes are induced in the semiconductor and the current increases. The device incorporating donor 1 shows a mobility of $5.9 \times 10^{-3} \mathrm{~cm}^{2} \mathrm{~V}^{-1} \mathrm{~s}^{-1}$ with a current on/off ratio of 11 . The threshold voltage $\left(V_{\mathrm{T}}\right)$ of this device is relatively high $(c a .30 \mathrm{~V})$, indicating the existence of rich carriers in the active layer under zero gate voltage which also might account for the low on/off current ratio. ${ }^{23}$ Unfortunately, no obvious field-effect was observed for the device prepared from 2 . This could be due to: (i) the composition of the thin film (which comprised polycrystalline grains rather than dendritic crystals) which may have impaired the charge carrier transport, or (ii) the shorter alkyl spacer in 2 


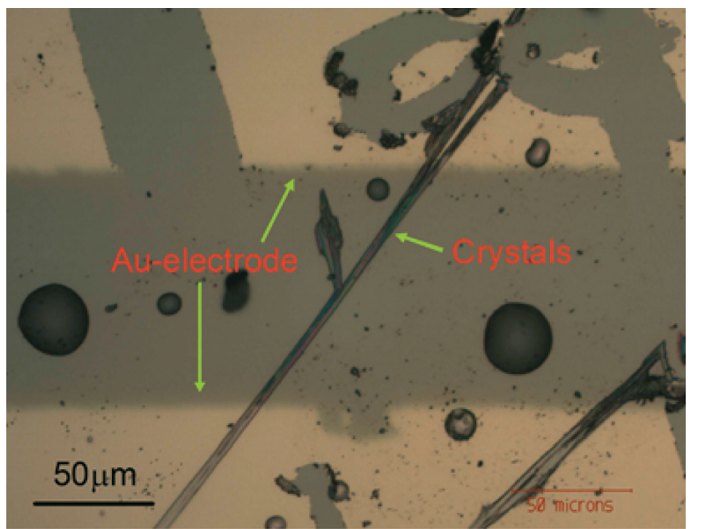

Fig. 14 Optical microscopy images of single crystals of 1 bridging microfabricated Au-electrodes.
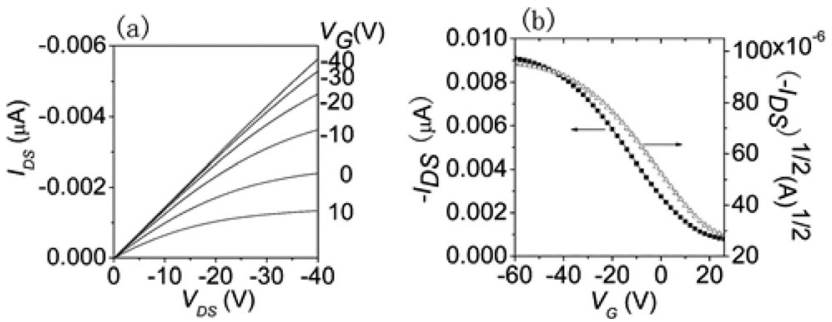

Fig. 15 (a) Output and (b) transfer characteristics of the OFET device based on 1, spin coated on an unmodified $\mathrm{SiO}_{2} / \mathrm{Si}$ substrate at room temperature.

that increases the slippage between donor molecules in the crystalline film, thus reducing efficient orbital overlap, weakening $\pi-\pi$ interactions and impairing the charge transport properties. Previous studies on TTF derivatives ${ }^{5 a, 9 a}$ have shown that there is a clear correlation between the crystal structure of the organic donors and device performance and that certain packing arrangements facilitate charge carrier mobilities in solution processable thin films. In this context, the arrangement of BEDT-TTF donors comprising of dimers stabilized via lateral $\mathrm{S} \cdots \mathrm{S}$ interactions is reported as one of the most suitable crystal packing arrangements for the preparation of OFETs. ${ }^{9 a}$ Unfortunately, the poor solubility of 3 in organic solvents coupled with its instability with respect to the vacuum deposition process rendered it an unsuitable candidate for incorporation into a solution processable device.

To summarize, charge transport in organic semiconductors arises from interplay between intra- and intermolecular interactions which depend on the chemical nature of the individual molecules as well as their organization within the crystal lattice. Doped thin films comprising of donor 1 or 2 in a polystyrene matrix displayed conductivity. The device performance of thin films prepared via spin coating donors 1 and 2 onto an unmodified silicon wafer substrate were the most sensitive to the structural changes in the organic linker with 1 displaying a mobility of $5.9 \times 10^{-3} \mathrm{~cm}^{2} \mathrm{~V}^{-1} \mathrm{~s}^{-1}$ with an on/off ratio of 11 , and 2 showing absolutely no FET response at all.

\section{Conclusions}

Three new BEDT-TTF derivatives with thiophene substituents have been prepared and characterized. This study highlights how subtle changes to the $\mathrm{CH}_{2}$ linker of a thiophene appended BEDT-TTF derivative has a marked impact upon the crystal packing of the neutral molecules and the electrical properties of the resulting thin films. It also reveals that the structural modifications necessary to optimise solubility (for device fabrication) and those which dictate supramolecular interactions (and charge carrier mobility for device performance) are frequently not mutually exclusive phenomena. Not only can small modifications to the organic framework of the organic molecules considerably change their molecular structures and thus their electronic properties, but also the solubilities of the molecules in conventional organic solvents can be dramatically altered, which is an important consideration when targeting solution processable materials for device applications. In addition, the self-organization of the polymer going from solution into the solid state is greatly dependent on the deposition process, which can lead to different packing arrangements and degrees of crystallinity that also has an impact on the electronic properties of the devices. ${ }^{29}$

Future studies to prepare and test the electron transport properties of symmetrical and unsymmetrical substituted BEDT-TTF derivatives bridged by both odd and even $\left(\mathrm{CH}_{2}\right)_{n}$ linkers are planned to shed more light on the relationship between molecular structure, thin film morphology and electrical performance in this family of compounds. Ongoing studies together with the Xerox Research Centre of Canada are in progress to new screen families of chemically tuneable BEDT-TTF derivatives, working towards the realization of soluble, crystalline donors and their incorporation into thin films for the fabrication of low cost, solution processable OFET devices.

\section{Acknowledgements}

Financial support from NSERC (Strategic Supplemental, M.P.), CRC (Tier II Canada Research Chair, M.P.), CFI and ORF (New Opportunities, M.P.), Brock University (International Seed Funds M.P.) (Minsitry of Ontario, Early Researchers Award, M.P) and Nottingham Trent University (J.D.W.) is gratefully acknowledged. We thank Prof. J.M. Rawson, (University of Windsor) for DFT calculations. We also gratefully acknowledge the XRCC for access to facilities and expertise to carry out the thin film and OFET part of this study.

\section{Notes and references}

1 (a) Y. Liu, C. Di, C. Du, Y. Liu, K. Lu, W. Qiu and G. Yu, Chem. - Eur. J., 2010, 16, 2231; (b) X. Gao, W. Wu, Y. Liu, S. Jiao, W. Qiu, G. Yu, L. Wang and D. Zhu, J. Mater. Chem., 2007, 17, 736; (c) H. E. A. Huitema, G. H. Gelnick, J. B. P. H. van der Putten, K. E. Kuijk, C. M. Hart, E. Cantatore, P. T. Herwig, A. J. J. M. van Breemen and 
D. M. de Leeuw, Nature, 2001, 414, 599; (d) U. Mitsche and P. Bauerle, J. Mater. Chem., 2000, 10, 1471; (e) B. Crone, A. Dodabalapur, A. Gelperin, L. Torsi, H. E. Katz, A. J. Lovinger and Z. Bao, Appl. Phys. Lett., 2001, 78, 2229; $(f)$ M. Mushrush, A. Facchetti, M. Lefenfeld, H. E. Katz and T. J. Marks, J. Am. Chem. Soc., 2003, 125, 9414.

2 (a) C. R. Kagan, D. B. Mitzl and C. D. Dimitrakopoulos, Science, 1999, 286, 945; (b) D. B. Mitzl, L. L. Kosbar, C. E. Murray, M. Copel and A. Afzall, Nature, 2004, 428, 299; (c) T. Shimoda, Y. Matsuki, M. Furusawa, T. Aoki, I. Yudasaka, H. Tanka, H. Iwasawa, D. Wang, M. Miyasaka and Y. Takeuchi, Nature, 2006, 440, 783.

3 J. Ferraris, D. O. Crown, V. Wakatka and J. H. Perlstein Jr., J. Am. Chem. Soc., 1973, 95, 948.

4 H. Jiang, X. Yang, Z. Cui, Y. Liu, H. Li, W. Hu and C. Kloc, CrystEngComm, 2014, 16, 5968.

5 (a) M. Mas-Torrent and C. Rovira, Chem. Soc. Rev., 2008, 37, 827; (b) W. Wu, Y. Liu and D. Zhu, Chem. Soc. Rev., 2010, 39, 1489; (c) S. Ukai, S. Igarashi, M. Nakajima, K. Marumoto, H. Ito, S. Kuroda, K. Nishimura, Y. Enomoto and G. Saito, Colloids Surf., A, 2006, 589, 284.

6 (a) F. Otón, R. Pfattner, E. Pavlica, Y. Olivier, G. Bratina, J. Cornil, J. Puigdollers, R. Alcubilla, X. Fontrodona, M. Mas-Torrent, J. Veciana and C. Rovira, CrystEngComm, 2011, 13, 6597; (b) F. Otón, R. Pfattner, E. Pavlica, Y. Olivier, E. Moreno, J. Puigdollers, G. Bratina, J. Cornil, X. Fontrodona, M. Mas-Torrent, J. Veciana and C. Rovira, Chem. Mater., 2011, 23, 851; (c) I. Doi, K. Goshome, E. Miyazaki and K. Takimiya, Chem. Lett., 2012, 41, 435; (d) R. Pfattner, M. Mas-Torrent, I. Bilotti, A. Brillante, S. Milita, F. Liscio, F. Biscarini, T. Marszalek, J. Ulanski, A. Nosal, M. Gazicki-Lipman, M. Leufgen, G. Schmidt, L. W. Molenkamp, V. Laukhin, J. Veciana and C. Rovira, Adv. Mater., 2010, 22, 4198; (e) M. Mas-Torrent, S. Masirek, P. Hadley, N. Crivillers, N. S. Oxtoby, P. Reuter, J. Veciana, C. Rovira and A. Tracz, Org. Electron., 2008, 9, 143; $(f)$ M. Katsuhara, I. Aoyagi, H. Nakajima, T. Mori, T. Kambayashi, M. Ofuji, Y. Takanishi, K. Ishikawa, H. Takezoe and H. Hosone, Synth. Met., 2005, 149, 219; $(g)$ M. Leufgen, O. Rost, C. Gould, G. Schmidt, J. Geurts, L. W. Molekamp, N. S. Oxtoby, M. Mas-Torrent, N. Crivillers, J. Veciana and C. Rovira, Org. Electron., 2008, 9, 1101; (h) X. Gao, W. Wu, Y. Liu, S. Jiao, W. Qiu, G. Yu, L. Wang and D. Zhu, J. Mater. Chem., 2007, 17, 736.

7 (a) M. Mas-Torrent, P. Hadley, S. T. Bromley, X. Ribas, J. Tarres, M. Mas, E. Molins, J. Veciana and C. Rovira, J. Am. Chem. Soc., 2004, 126, 8546; (b) M. Mas-Torrent and C. Rovira, in Functional Supramolecular Architectures for Electronics and Nanotechnology, ed. P. Samori and F. Cacialli, Wiley-VCH, 2011, pp. 651-677.

8 P. Batail, Chem. Rev., 2004, 104, 4887.

9 (a) M. Mas Torrent and C. Rovira, J. Mater. Chem., 2006, 16, 433; (b) Organic field-effect Transistors, ed. Z. Bao and J. Lockin, CRC Press, 2007.

10 (a) M. Chahma, K. Macnamara, A. van der Est, A. Alberola, V. Polo and M. Pilkington, New J. Chem., 2007, 31, 1973; (b)
M. Chahma, N. Hassan, A. Alberola, H. Stoeckli-Evans and M. Pilkington, Inorg. Chem., 2007, 46, 3807; (c) A. Alberola and M. Pilkington, Curr. Org. Synth., 2009, 6, 66; (d) I. Awheda, S. J. Krivickas, S. Yang, L. Martin, M. A. Guziak, A. C. Brooks, F. Pelletier, M. L. Kerneau, P. Day, P. N. Horton, H. Akutsu and J. D. Wallis, Tetrahedron, 2013, 69, 8738; (e) F. Pop, S. Larrousi, T. Cauchy, C. J. Gomez-Garcia, J. D. Wallis and N. Avarvari, Chirality, 2013, 25, 466.

11 (a) Y. Kawasugi, H. M. Yamamoto, N. Tajima, T. Fukunaga, K. Tsukagoshi and R. Kato, Phys. Rev. Lett., 2009, 103, 116801; (b) M. Kimata, T. Ishihara, A. Ueda, H. Mori and H. Tajima, Synth. Met., 2013, 173, 43.

12 Q. Wang, P. Day, J. P. Griffiths, H. Nie and J. D. Wallis, New J. Chem., 2006, 1790.

13 (a) R. J. Brown, A. C. Brooks, J.-P. Griffiths, B. Vital, P. Day and J. D. Wallis, Org. Biomol. Chem., 2007, 3172; (b) H. Li, D. Zhang, B. Zhang, Y. X. Yao, W. Xu, D. Zhu and Z. Wang, J. Mater. Chem., 2000, 10, 2063; (c) I. Dori, K. Goshome, E. Miyazaki and K. Takimiya, Chem. Lett., 2012, 41, 435.

14 (a) G. M. Sheldrick, Acta Crystallogr., Sect. A: Found. Crystallogr., 2008, 64, 112; (b) SAINT, v. 6.02, Bruker AXS Inc., Madison, WI, 1999G; (c) APEX-II, Bruker AXS Inc., Madison, Wisconsin, USA.

15 G. M. Sheldrick, SADABS, v. 2.05, University of Göttingen, Germany.

16 SHELXTL package for crystal structure solution and refinement, Bruker AXS Inc., Madison, Wisconsin, USA.

17 R. Ditchfield, W. J. Hehre and J. A. Pople, J. Chem. Phys., 1971, 54, 724.

18 C. Lee, W. Yang and R. G. Parr, Phys. Rev. B: Condens. Matter Mater. Phys., 1988, 37, 785.

19 Jaguar version 8.0, Schrödinger LLC, New York, NY, 2013.

20 (a) M. Mas-Torrent, E. Laukhina, C. Rovira, J. Veciana, V. Tkacheva, L. Zorina and S. Khasanov, Adv. Funct. Mater., 2001, 11, 299; (b) A. Tracz, J. K. Jeszka, A. Sroczyńska, J. Ulański and T. Pakula, Adv. Mater. Opt. Electron., 1996, 6, 335; (c) M. Mas-Torrent, E. Ribera, V. Tkacheva, I. Mata, E. Molins, J. Vidal-Gancedo, S. Khasanov, L. Zorina, R. Shibaeva, R. Wojciechowski, J. Ulanski, K. Wurst, J. Veciana, V. Laukhin, E. Canadell, E. Laukhina and C. Rovira, Chem. Mater., 2002, 14, 3295; (d) E. Laukhina, V. Tkacheva, S. Khasanov, L. Zorina, J. Gómez-Segura, A. P. D. Pino, J. Veciana, V. Laukhin and C. Rovira, ChemPhysChem, 2006, 7, 920; (e) P. Polanowski, A. Tracz, J. Ulański and E. Dormann, Synth. Met., 2000, 109, 235.

21 W. Wu, Y. Liu and D. Zhu, Chem. Soc. Rev., 2010, 39, 1489.

22 (a) P. Polanowski, A. Tracz, J. Ulański and E. Dormann, Synth. Met., 2000, 109, 235; (b) J. K. Jeszka, A. Tracz, A. Sroczyńska, M. Kryszewski, H. Yamochi, S. Horiuchi, G. Saito and J. Ulański, Synth. Met., 1999, 106, 75; (c) S. Hornchi, H. Yamochi, G. Saito, J. K. Jeszka, A. Tracz, A. Sroczyńska and J. Ulański, Mol. Cryst. Liq. Cryst., 1997, 296, 365; (d) J. K. Jeszka and A. Tracz, Polym. Adv. Technol., 1992, 3, 139.

23 (a) J. K. Jeszka and A. Tracz, Polym. Adv. Technol., 1992, 3, 139; (b) E. Laukhina, V. Tkacheva, I. Chuev, E. Yagubskii, 
J. Vidal-Gancedo, M. Mas-Torrent, C. Rovira, J. Veciana, S. Khasanov, R. Wojciechowski and J. Ulanski, J. Phys. Chem. B, 2001, 105, 11089; (c) M. Wiatrowski, E. Dobruchowska, W. Maniukiewicz, U. Pietsch, J. Kowalski, Z. Szamel and J. Ulanski, Thin Solid Films, 2010, 518, 2266; (d) X. K. Gao, W. P. Wu, Y. Q. Liu, W. F. Qiu, X. B. Sun, G. Yu and D. B. Zhu, Chem. Commun., 2006, 2750.

24 P. B. Shea and J. Kanicki, J. Appl. Phys., 2005, 98, 014503.

25 S. Yang, A. C. Brooks, L. Martin, P. Day, M. Pilkington, W. Clegg, R. W. Harrington, L. Russo and J. D. Wallis, Tetrahedron, 2010, 66, 6977.
26 Q. Wang, L. Martin, A. J. Blake, P. Day and J. D. Wallis, Inorg. Chem., 2014, submitted.

27 A. Tracz, J. K. Jeska, J. Ulański, T. Pakula and J. P. Rabe, Synth. Met., 1998, 94, 17.

28 S. M. Sze, Physics of Semiconductor Devices, Wiley, New York, 1981.

29 (a) E. Mena-Osteritz, Adv. Mater., 2002, 14, 609; (b) E. Mena-Osteritz, A. Meyer, B. M. W. Langeveld-Voss, R. A. J. Janssen, E. W. Meijer and P. Bäuerle, Angew. Chem., Int. Ed., 2000, 39, 2679; (c) S. Cataldo and B. Pignataro, Materials, 2013, 6, 1159. 